Communications in Physics, Vol.21, No. 4 (2011), pp. 379-384

\title{
ZnO/CdS BILAYER USED FOR ELECTRODE IN PHOTOVOLTAIC DEVICES
}

\author{
DANG TRAN CHIEN \\ Hanoi University of Natural Resources and Environment \\ PHAM DUY LONG AND PHAM VAN HOI \\ Institute of Materials Science, VAST
}

\begin{abstract}
In this article we present the fabrication and characterization of the nanoporous $Z n O$ and/or $\mathrm{ZnO} / \mathrm{CdS}$ thin films onto indium doped-tin oxide (ITO) substrates, based on the thermal evaporation technique followed by thermal treatment. The preparation method was relatively simple and low-cost for large scale uniform coating to produce clean, dense and strong adhesion to substrate thin films. The nanostructured $\mathrm{ZnO}$ and $\mathrm{ZnO} / \mathrm{CdS}$ thin films were characterized by $X$-ray diffraction (XRD) and field emission scanning electron microscope (FE-SEM). The nanostructured $\mathrm{ZnO} / \mathrm{CdS}$ bilayer film was used in a photo-electrochemical (PEC) cell as a working electrode and a Pt net as a counter electrode. The results show that the photovoltaic cell with nanostructured $\mathrm{ZnO} / \mathrm{CdS}$ bilayer film electrode has significantly improved photoelectric capability in comparison with that of $\mathrm{ZnO}$ electrode.
\end{abstract}

\section{INTRODUCTION}

Zinc oxide $(\mathrm{ZnO})$ is an n-type semiconductor of wurtzite structure. $\mathrm{ZnO}$ thin films have many applications in gas sensors, photocatalysis, dye-sensitized solar cells and piezoelectric devices [1]. Unfortunately, the band gap of $\mathrm{ZnO}$ is so large (around $3.37 \mathrm{eV}$ ) [2] that it can only absorb a small part of visible light. Therefore, it is necessary to sensitize the $\mathrm{ZnO}$ nanoelectrodes. Semiconductors with narrow band gap have recently attracted much attention due to their excellent properties, such as higher absorption, greater stability and adjustable band gap [3]. Among the various semiconductors, CdSe, CdTe, CuInS 2 , InP, etc, are used as sensitizers .[4], CdS has shown much promise as an effective sensitizer [5]. It is the most widely studied nanocrystalline semiconductor as a photoanode in photoelectrochemical cells because of its suitable band gap, long lifetime, important optical properties, excellent stability and ease of fabrication [6]. In the semiconductor-sensitized solar cell (SSSC), a light-absorbing semiconductor deposited on the porous transparent oxide takes the place of the dye [3]. In this work, CdS was used to sensitize ZnO nanostructures.

Various methods have been used for the production of $\mathrm{ZnO}$ nanostructures such as chemical vapor deposition [7], thermal evaporation [8], pulse-laser deposition [9], DC and/or radio frequency (RF) sputtering [10], sol-gel and wet chemical method [11], hydrothermal method [12], etc. In this work we used vacuum evaporation technique combined with thermal process for fabrication of nanostructured $\mathrm{ZnO}$ films. In comparison 
with various techniques, thermal evaporation is a relatively simple one for large scale uniform coating to produce clean, dense and strong adhesion to substrate thin films.

\section{EXPERIMENTS}

The optically transparent and electrically conductive indium tin oxide (ITO) coated glass substrate with a sheet resistance of $30 \Omega$ per square was rinsed ultrasonically successively in acetone, ethanol, and distilled water. A $100 \mathrm{~nm}$ thick layer of $\mathrm{Zn}$ was deposited on ITO substrates by thermal evaporation at a pressure of $10^{-2}$ torr. Then the thin film $\mathrm{Zn}$ was annealed at $450^{\circ} \mathrm{C}$ in air for $7 \mathrm{~h}$. Thin film of CdS with thickness of about 200 $\mathrm{nm}$ was fabricated, by the same method as that for $\mathrm{Zn}$ film, onto the pre-fabricated $\mathrm{ZnO}$ films. The deposition rate was $0.2 \mathrm{~nm} / \mathrm{s}$ and the thin film thickness was measured during deposition using a conventional quartz crystal monitor. To obtain good crystallinity, the thin CdS films were annealed at $400^{\circ} \mathrm{C}$ in air for $1 \mathrm{~h}$. The surface morphology of the samples was investigated by using a Field Emission Scanning Electron Microscope (FE-SEM) Hitachi S-4800. The Ultraviolet-visible (UV-VIS) absorption spectra was performed by using a Jasco UV-VIS-NIR V570 spectrometer, X-ray diffractograms were recorded on a Siemens D-5000 diffractometer using CuK $\alpha$ radiation with the wavelength of $1.5406 \AA$. In photoelectronic studies, a two-electrode PEC cell was used. This comprises ITO/ZnO or ITO/ZnO/CdS used as working electrode (working area is $1 \mathrm{~cm}^{2}$ ) and a Pt net electrode separated by an electrolyte containing $1 \mathrm{M} \mathrm{KCl}$ and $0.1 \mathrm{M} \mathrm{Na} 2 \mathrm{~S}$. The photocurrent was measured on an Auto-Lab Potentiostat PGS-30. A halogen lamp of $300 \mathrm{~W}$ with visible filter in the wavelength range of $380-800 \mathrm{~nm}$ was used as an irradiation source. The illumination power density on the electrodes was of $20 \mathrm{~mW} \cdot \mathrm{cm}^{-2}$ was used as an irradiation source in the Lab. The photoelectrochemical cells were irradiated by sunlight of power density of $100 \mathrm{~mW} \cdot \mathrm{cm}^{-2}$ in open air.

\section{RESULTS AND DISCUSSION}

\section{III.1. Morphology and structural characterizations of nanostructure $\mathrm{ZnO} / \mathrm{CdS}$ bilayer films}

The FE-SEM images of the surface of nanostructured $\mathrm{ZnO}$ film is presented in Fig. 1(a). The surface of nano-particle CdS film on the ITO/ZnO substrate is shown in Fig. 1(b). From Fig. 1(a) it is seen that the film consists of flower-like grains continuously and homogeneously deposited on the substrate surface. As shown in Fig. 1(b) a homogeneous CdS film with good quality deposited onto ITO/ZnO substrate and a very rough surface was observed. The film has a nanoporous structure which is supposedly beneficial to diffusion of electrolytes and effective scattering of incident sunlight when it is applied to photoanodes of SSSC. Therefore, the thermal evaporation technique can effectively improve the distribution of CdS nanoparticles on the ITO/ZnO surface and into the porosity of the thin film. This may favor the absorption of irradiation light by semiconductor .

The XRD patterns of $\mathrm{ZnO}$ film and $\mathrm{ZnO} / \mathrm{CdS}$ bilayer film on glass substrates are shown in Fig. 2(a) and Fig. 2(b), respectively. Peaks in Fig. 2(a) with $2 \theta$ values of $31.62^{\circ}$, $34.28^{\circ}, 36.42^{\circ}$ and $47.40^{\circ}$ exactly identified for the hexagonal wurtzite structure of $\mathrm{ZnO}$. This is in good agreement with references [1]. Fig. 2(b) shows peaks at $2 \theta$ of about $24.83^{\circ}$, 


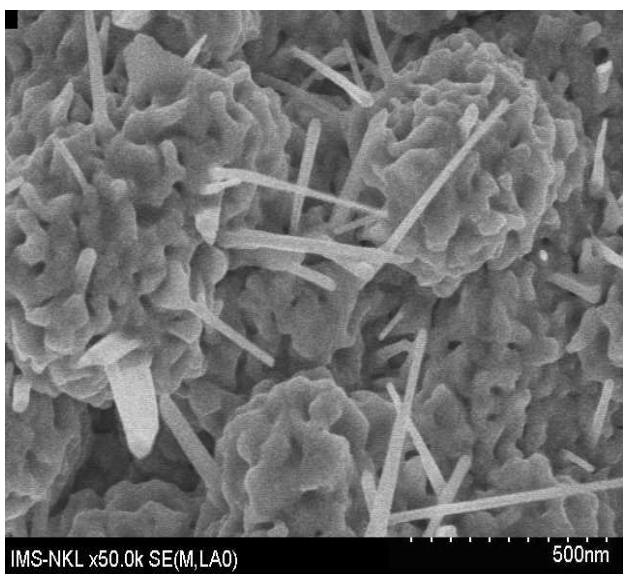

(a)

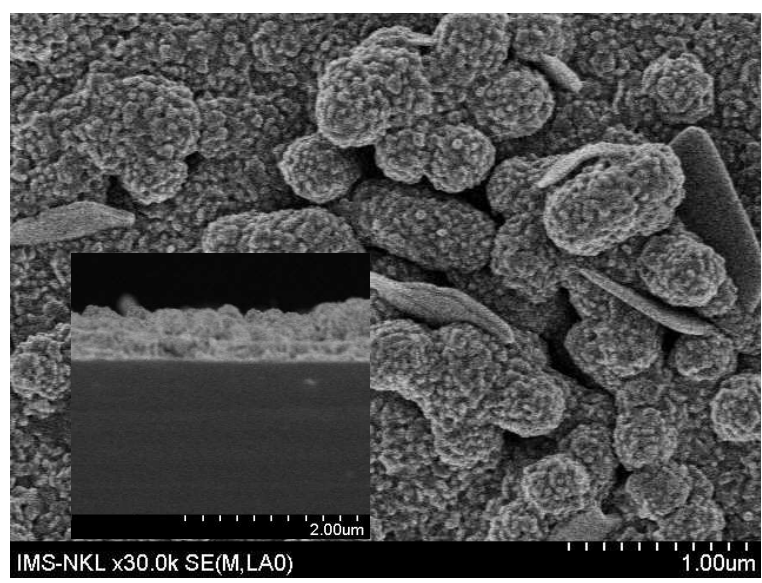

(b)

Fig. 1. FE-SEM images of the nanostructured $\mathrm{ZnO}$ (a), $\mathrm{ZnO} / \mathrm{CdS}$ films (b). The inset shows the cross-sectional of the $\mathrm{ZnO} / \mathrm{CdS}$ bilayer

$26.52^{\circ}, 28.21^{\circ}, 36.65^{\circ}, 43.73^{\circ}$ and $51.87^{\circ}$ corresponding to the (100), (002), (101), (102), (110) and (112) planes, respectively and identified to a hexagonal phase for CdS. This result agrees well with Ref. [13]. There are no peaks for other zinc compounds detected in the spectra. This result clearly shows that $\mathrm{ZnO} / \mathrm{CdS}$ bilayer film had been successfully prepared.

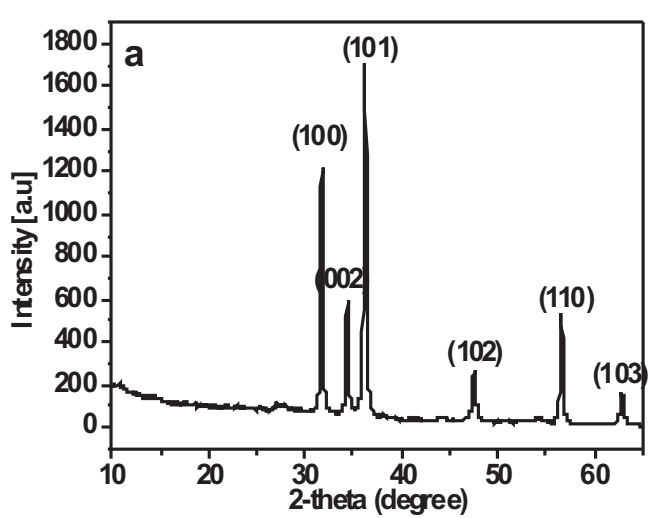

(a)

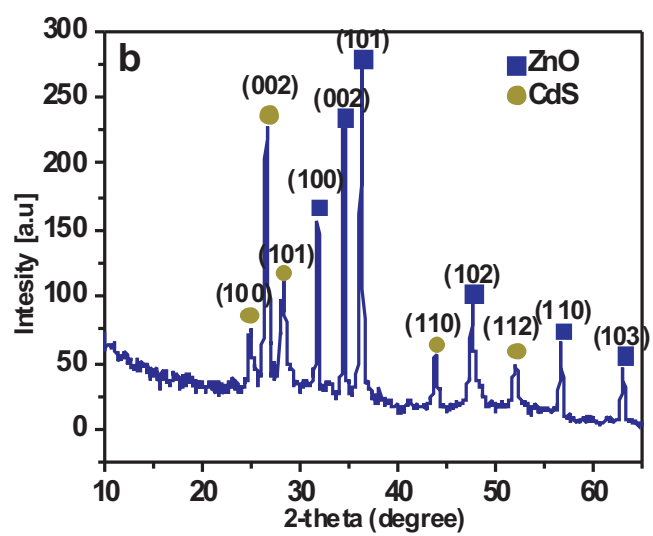

(b)

Fig. 2. The XRD patterns of $\mathrm{ZnO}$ film (a) and $\mathrm{ZnO} / \mathrm{CdS}$ bilayer (b) 


\section{III.2. Absorption spectra of the $\mathrm{ZnO}$ and $\mathrm{ZnO} / \mathrm{CdS}$ bilayer thin films}

Light absorption property is one of the most important properties for photo-electrodes which may determine the overall conversion efficiency of solar cell. Fig. 3 shows the UVVIS absorption spectra of $\mathrm{ZnO}$ thin film and $\mathrm{CdS}$ thin film on the $\mathrm{ZnO}$ substrate. As it can be seen from the figure, the $\mathrm{ZnO}$ thin film absorbs light mainly in the wavelength range from $365 \mathrm{~nm}$ to $380 \mathrm{~nm}$. The absorption edge of $\mathrm{ZnO} / \mathrm{CdS}$ bilayer film falls into the visible region at the wavelength of about $540 \mathrm{~nm}$. The absorption edge for the CdS film on $\mathrm{ZnO}$ substrate was shifted to longer wavelength region, known as red-shift.

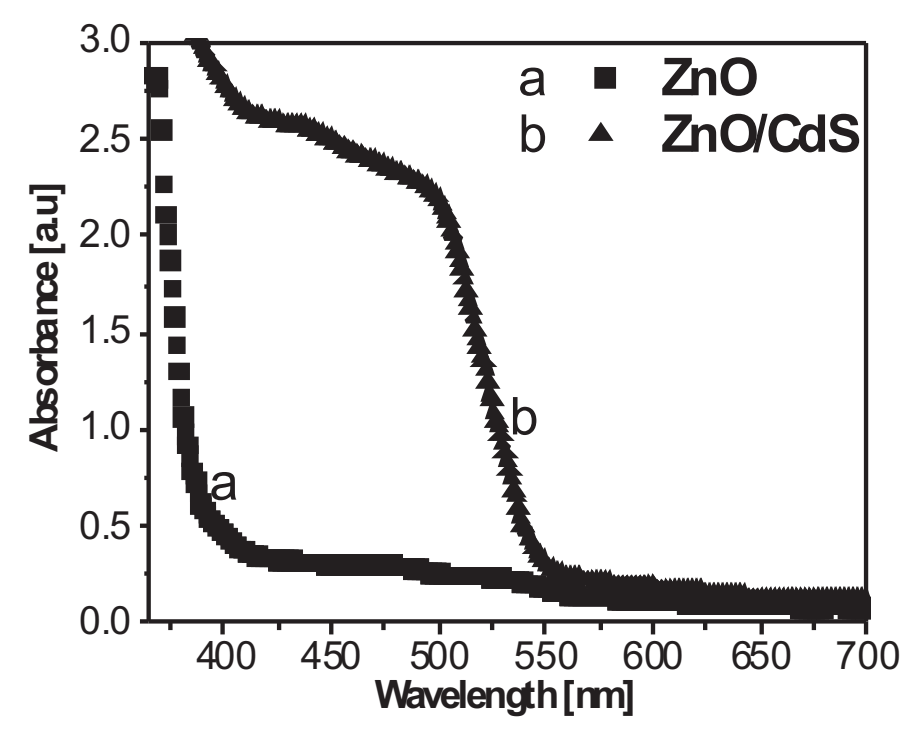

Fig. 3. UV-VIS absorption spectra of nanostructured $\mathrm{ZnO}$ and $\mathrm{ZnO} / \mathrm{CdS}$ bilayer films.

\section{III.3. Photoelectronic performance of nanostructured $\mathrm{ZnO} / \mathrm{CdS}$ bilayer films}

Figure 4 shows the photocurrent-potential behaviors of the photoelectrochemical cell with each of the prepared samples used as working electrodes in turn under illumination. The photocurrent-potential behavior of $\mathrm{ITO} / \mathrm{TiO}_{2} / \mathrm{CdS}$ was our previously result in Ref. [14]. From figure 4, it is can be seen that the open-circuit photovoltage $\left(\mathrm{V}_{o c}\right)$ and the short-circuit photocurrent density $\left(\mathrm{J}_{s c}\right)$ of ITO/ZnO, ITO/ $\mathrm{TiO}_{2} / \mathrm{CdS}$ and ITO/ZnO/CdS are $\left(117 \mathrm{mV}, 27 \mu \mathrm{A} . \mathrm{cm}^{-2}\right),\left(300 \mathrm{mV}, 35 \mu \mathrm{A} \cdot \mathrm{cm}^{-2}\right)$ and $(680 \mathrm{mV}, 1200$ $\left.\mu \mathrm{A} . \mathrm{cm}^{-2}\right)$, respectively. This is clearly seen that the photo-electrochemical cell made from films consisting only of $\mathrm{ZnO}$ has very low values for $V_{o c}$ and $J_{s c}$ whereas on coating a thin film of CdS, both $V_{o c}$ and $J_{s c}$ ' increase dramatically. The resulting nanoporous $\mathrm{ZnO} / \mathrm{CdS}$ film produced a photocurrent of $1200 \mu \mathrm{A} . \mathrm{cm}^{-2}$, which was three time more than that of macroporous $\mathrm{ZnO} / \mathrm{CdS}$ [15]. Figure $4 \mathrm{~b}$ presents the photocurrent-potential behavior of ITO $/ \mathrm{ZnO} / \mathrm{CdS}$ with working area of $5 \mathrm{~cm}^{2}$ under irradiation of sunlight with energy 
density of $100 \mathrm{~mW} \cdot \mathrm{cm}^{-2}$ in open air. The open-circuit photovoltage and the short-circuit photocurrent density were of $680 \mathrm{mV}$ and $6.23 \mathrm{~mA} . \mathrm{cm}^{-2}$, respectively. The fill-factor of our PEC was of 0.31-0.33 then the energy conversion efficiency was of $1.3-1.4 \%$.

The open-circuit photovoltage of $680 \mathrm{mV}$ and the photocurrent of $1200 \mu \mathrm{A}$ produced by nanoporous $\mathrm{ZnO} / \mathrm{CdS}$ bilayer film of $1 \mathrm{~cm}^{2}$-illuminated area show that the nanosize $\mathrm{CdS}$ effectively sensitized the nanoporous $\mathrm{ZnO}$. This can be explained as follows, the electron affinity of the CdS is higher than that of the ZnO. Therefore, according to Anderson's model, a type-II heterojunction is well formed between $\mathrm{CdS}$ and $\mathrm{ZnO}$ [16]. The electrons from the conduction band of CdS are quickly transferred to the conduction band of $\mathrm{ZnO}$. Once the electrons diffuse into the conduction band of $\mathrm{ZnO}$, the probability of its decay is small because there can be no free hole in $\mathrm{ZnO}$ under visible excitation. As a result, the electrons accumulate in the conduction band of the $\mathrm{ZnO}$ and the holes accumulate in the valence band of the CdS. In this way, the charge separation is achieved [16]. The redox couple in the electrolyte, after reducing the oxidized dye, can be renewed in the counterelectrode, making the photoelectrochemical cell regenerative [5]. It is clearly seen that the coupling of $\mathrm{ZnO}$ with $\mathrm{CdS}$ can significantly enhance the separation of the electron and hole pairs, therefore, ameliorate the photoelectric performance of the $\mathrm{ZnO} / \mathrm{CdS}$ bilayer films. These results are promising for improving the efficiency of photovoltaic devices.

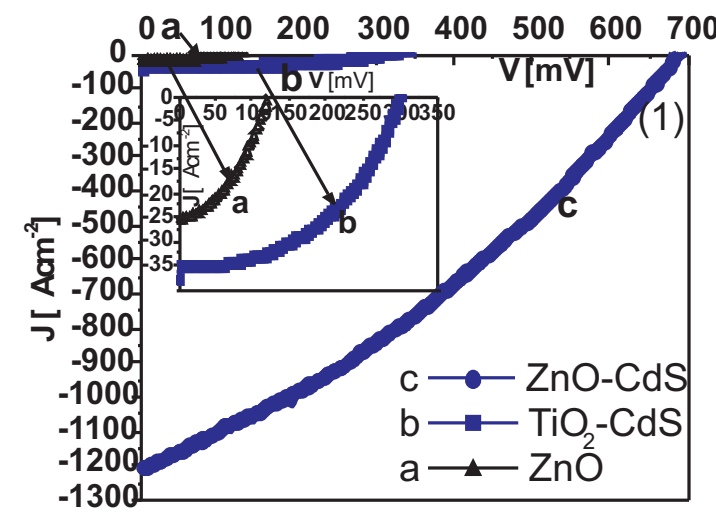

(a)

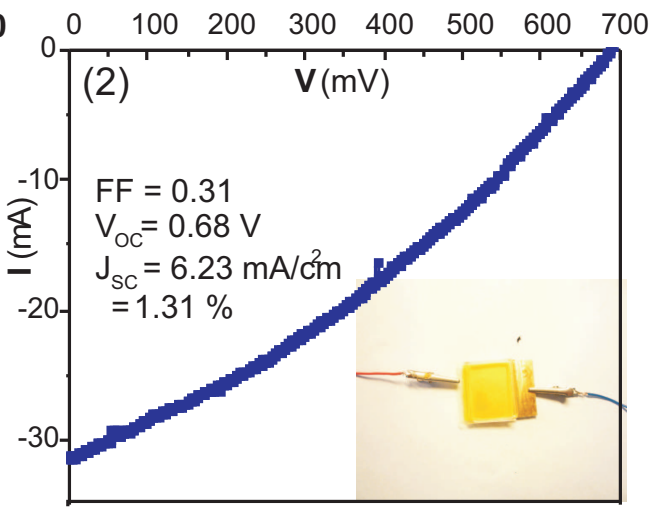

(b)

Fig. 4. Photocurrent-potential $(\mathrm{J}-\mathrm{V})$ behaviors of $\mathrm{ZnO}(\mathrm{a}), \mathrm{TiO}_{2} / \mathrm{CdS}(\mathrm{b})$ and the $\mathrm{ZnO} / \mathrm{CdS}(\mathrm{c})$ electrodes, respectively. The inset shows zoom in $(\mathrm{J}-\mathrm{V})$ of $\mathrm{ZnO}$ and $\mathrm{TiO}_{2} / \mathrm{CdS}$ electrodes. (b)Photocurrent-potential $(\mathrm{J}-\mathrm{V})$ behaviors of Photovoltaic cells irradiated by sunlight in open air. The inset shows the image of device.

\section{CONCLUSIONS}

Nanoporous $\mathrm{ZnO} / \mathrm{CdS}$ thin films have been successfully prepared by a thermal evaporation technique combined with thermal process. This method is relatively simple and low-cost technique for large scale uniform coating nanoporous thin film on the substrate. The PEC using the nanoporous $\mathrm{ZnO} / \mathrm{CdS}$ bilayer thin film as an electrode produced the 
energy conversion efficiency of 1.3-1.4\%. The nanoporous $\mathrm{ZnO} / \mathrm{CdS}$ bilayer thin film produced photocurrent density of $6.23 \mathrm{~mA} \cdot \mathrm{cm}^{-2}$ has possessed more excellent photoelectrochemical performance than that of ITO $/ \mathrm{ZnO}$, ITO $/ \mathrm{TiO}_{2} / \mathrm{CdS}$ films and macroporous $\mathrm{ZnO} / \mathrm{CdS}$. It is believed that nanostructured $\mathrm{CdS}$ films effectively sensitizing $\mathrm{ZnO}$ nanoporous structures can be used in fabricating high efficiency photovoltaic devices.

\section{ACKNOWLEDGMENTS}

This work is supported in part by the National Program for Basic researches in

Natural Science of Vietnam (NAFOSTED) under contract No. 103.02.82.09. A part of the work was done with the help of the National Key Laboratory in Electronic Materials and Devices, Institute of Materials Science, Vietnam Academy of Science and Technology, Vietnam.

\section{REFERENCES}

[1] Y. Jiang, M. Wu, X. Wu, Y. Sun, and H. Yin, Materials Letters 63 (2009) 275.

[2] N. Boukos, C. Chandrinou, K. Giannakopoulos, G. Pistolis, and A.Travlos, Applied Physics A 88 (2007) 35 .

[3] G. Hodes, The Journal of Physical Chemistry C 112 (2008) 17778.

[4] D. Liu and P.V. Kamat, The Journal of Physical Chemistry 97 (1993) 10769.

[5] Y-J. Chi, H-G. Fu, L-H. Qi, K-Y. Shi, H-B. Zhang, and H-T.Yu, Journal of Photochemistry and Photobiology A: Chemistry 195 (2008) 357.

[6] J. Touscaronková, D. Kindl, and J. Touscaronek, Physica Status Solidi (a) 142 (1994) 539.

[7] H. Jianhua and R.G. Gordon, J. Appl. Phys. 71 (1992) 351309.

[8] M. Jin, J. Feng, Z. De-heng, M. Hong-lei, and L. Shu-ying, Thin Solid Films 357 (1999) 98.

[9] P.M. Verghese and D.R. Clarke, J. Mater. Res. 14 (1999) 1039.

[10] J-L. Chung, J-C. Chen, and C-J. Tseng, Journal of Physics and Chemistry of Solids 69 (2008) $535-539$

[11] J. Liu, X. Huang, J.Duan, H. Ai, and P.Tu, Materials Letters 59 (2005) 3710.

[12] C. Meijuan, T. Yiwen. L. Bihui, and L. Lijuan, J. Nanosci. Nanotechnol. 9 (2009) 1505.

[13] A. Aguilera, V. Jayaraman, S. Sanagapalli, S. Singh, V. Jayaraman, K. Sampson, and V. P. Singh, Solar Energy Materials \& Solar Cells 90 (2006) 713.

[14] T.C. Dang, D.L. Pham, H.C. Le, and V. H. Pham, Adv. Nat. Sci.: Nanosci. Nanotechnol. 1 (2010) 0150021.

[15] T.C. Dang, D.L. Pham, H.L. Nguyen, and V. H. Pham, Adv. Nat. Sci: Nanosci Nanotechnol. 1 (2010) 0350101.

[16] J. Nayak, S. N. Sahu, J. Kasuya, and S. Nozaki, Applied Surface Science 254 (2008) 7215.

Received 21 June 2011. 